\title{
Performance Evaluation and Optimization of Single Barrel Cassava Grating Machine on Selected Fresh and Stored Cassava Species
}

\author{
Okonkwo Ugochukwu C. ${ }^{1}$, Onwukwe Michael $^{2}$, Oriaku Edwin C. ${ }^{3}$, and \\ Okafor Christian $\mathrm{E}^{4}$ \\ ${ }^{1,2}$ Department of Mechanical Engineering, Nnamdi Azikiwe University Awka \\ ${ }^{3,4}$ Projects Development Institute, (PRODA) Emene, Enugu
}

\begin{abstract}
This study carried out the performance and optimization evaluation of single barrel cassava grating machine on selected fresh and stored cassava species. Three cassava species were sourced from Michael Okpara University of Agriculture Umudike, Nigeria, namely UMUCASS 36, UMUCASS 37, UMUCASS 38. This species were used at different levels of moisture content, $74.4 \% \mathrm{db}$ and $61.4 \% \mathrm{db}$ depicting the average moisture contents obtained for fresh and stored cassava, respectively. The experimental design employed was a twolevel-two factor full factorial central composite response design, including 13 experimental runs each for dry and stored samples. The experimental design was carried out using Design Expert Software version 7.0.7.1 to determine the optimum operating conditions. The software was used to determine the levels of factors which gave optimum performance efficiency by obtaining a quadratic models for both dry and stored cassava. The correlation between the experimental and predicted performance efficiency was checked through a plot of experimental and predicted results and the data points were closely distributed along a diagonal line indicating good agreement. Hence, the generated models have sufficient accuracy to predict the machine performance. The machine performance was optimized to obtain optimal conditions for the grater. The analysis of the performance of the grating machine predicted optimum operating condition as follows: 6mm abrasive surface hole sizes for both fresh and stored cassava, feed rate of $11.5 \mathrm{~kg} / \mathrm{min}$ and $11.6 \mathrm{~kg} / \mathrm{min}$ for fresh and stored samples respectively, measured efficiency of $96.2 \%$ and $98.0 \%$ for fresh and stored samples and predicted efficiency of 96.6 and 98.6 for fresh and stored cassava samples, respectively. These results prove that the grating machines perform better with stored samples with less moisture content.
\end{abstract}

Keywords: Grating Machine, fresh cassava, stored cassava, abrasive hole, performance evaluation, grating efficiency

\section{Introduction}

Nigeria has been world-leading producer of cassava with an estimated annual production of 2.6 million tons from an estimated area of 1\% million hectares of land (IITA, 1990) and (Agbetoye, 2005). The major problem of cassava is that it is extremely perishable and the harvested tuber must be processed to curb postharvest losses (Davies, 1991). According to food and Agriculture Organization (FAO, 2007) the estimated industrial cassava use was approximately, 16 percent of cassava root production and was utilized as an industrial raw material in 2001 in Nigeria. Around the world, cassava is a vital stable food for about 500 million people. Cassava's starching roots produce more food energy permit of land than any other staple crop. It is one of the most valuable staple food source for tens of millions of people in the West African sub-region (Adejumo et al., 2011).

Mechanization of cassava processing operations will no doubt play a pivotal role in removing the negative attributes of the traditional processing techniques and promote timely large scale processing of the tubers in hygienic environment. Chinsman and Fiagan (1987) reported that proper processing and preservation of harvested produce minimize post harvest losses and thus help to off-set shortage in food supply. The transformation of cassava tubers into pulp form is called Grating (FAO, 2004). Mechanizing cassava processing operations require the design and development of equipment such as cassava peelers, graters, chippers, dewatering machines, pelletizers, dryers etc. Several attempts have been made at designing cassava graters. The traditional method of cassava grating is made of a perforated metal sheet of aluminum or galvanized sheet and the peeled cassava tuber is robbed on the rough surface, while the grated product is collected in a container (Oyesola 1981). Various types of cassava grating machines have been developed (Akinyemi and Akinlua, 1999; Akande et al., 2005; Ndaliman, 2006; Malomo et al, 2014).

As regards the performance evaluation of cassava graters, not much work has been done beyond testing for the capacity and efficiency of the graters (Ndaliman, 2006; Akade 2008; Akanbi, 2014). Malomo et al (2014) went more in-depth by carrying out performance evaluation of an automated combined cassava 
grater/slicer using two cassava species. He found that machine was affected by the specie and the size of the cassava tube. In this study, in-depth study of performance evaluation selected fresh and stored cassava using three cassava species will be carried out followed by scientific design of experiment to obtain optimized conditions.

\section{Materials And Methods}

Grating Machine: The single barrel grater consists of one inlet hopper, a transmission shaft, wooden barrel wrapped with perforated aluminum plate and two bearings which is driven by a $5 \mathrm{hp}$ rated electric motor through inclined v-belt and pulley drive shown in Figure 1. Cassava Tubers: Three species of cassava were used in the study. They are UMUMCASS 36, UMUCASS 37 and UMUCASS 38 and were all sourced from Michael Okpara University of Agriculture Umudike, Nigeria. Also, Weighing Balance and Oven were used for weighing of specimen and testing of moisture content respectively.

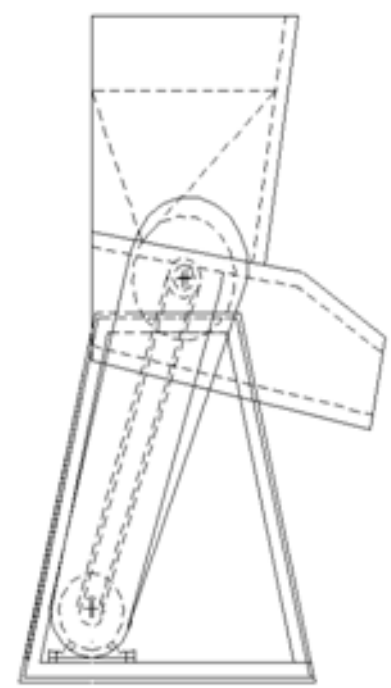

FRONT VIEW

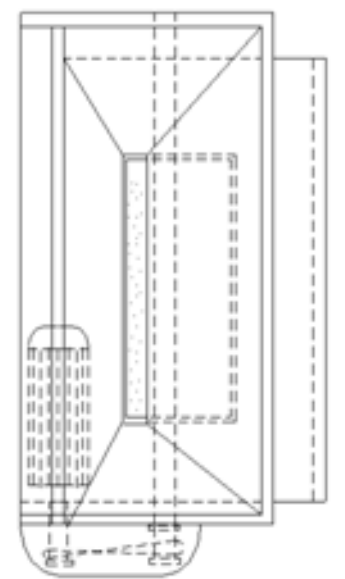

PLANVIEW

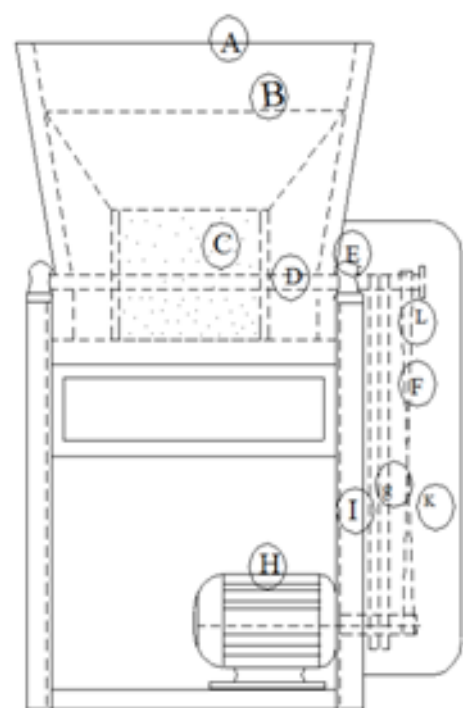

END VEW

\begin{tabular}{|c|c|}
\hline \multicolumn{2}{|r|}{ LEGEND } \\
\hline A & LOADENG PLATFORM \\
\hline B & LOADNGPLATE \\
\hline C & GRAIING BARREI \\
\hline D & TRUSSATRONSHWT \\
\hline E & BEARING \\
\hline F & Cross BetT \\
\hline G & OFENBET \\
\hline $\mathrm{H}$ & ELECTRICMOIOR \\
\hline I & STRUCTURAL STAND \\
\hline 3 & OUTLET CHUTE \\
\hline $\mathrm{K}$ & COVERPLATE \\
\hline L & PUUEY \\
\hline
\end{tabular}

Figure 1: Autographic drawing of the single barrel grating machine

Principles of Single Barrel Grater: The single barrel grater was designed in such a way that one electric motor provides the primary motion required to power the machine. This motion produces a torque which is transmitted to the grating barrel via the belt, pulley, shaft, and bearing. The grating barrel is mounted in such a manner as to allow a critical gap between it and the rectangular plate attached adjacent to one side of the inlet hopper. This plate just like the grating barrel has an abrasive edge which also helps to ensure proper grating of the sample. The single barrel operates in one direction. 


\section{Sample Preparation and Experimental Procedure}

Fresh samples of each specie of cassava was peeled and washed clean to remove dirt and any other foreign materials. The moisture content of the cassava tuber was determined using AOAC 2002 Hot air oven method. Thus samples weighing up to $150 \mathrm{~g}$ were placed on a petri dish of known weight and the oven was set to a temperature of $105^{\circ} \mathrm{C}$ and the sample placed on a petri dish was allowed to dry in the oven till a constant weight. Then tubers were weighed and $20 \mathrm{~kg}, 40 \mathrm{~kg}, 60 \mathrm{~kg}$, and $80 \mathrm{~kg}$ samples were kept in plastic bowls to be used for the experiment. The grater with the abrasive surfaces of $4 \mathrm{~mm}, 5 \mathrm{~mm}, 6 \mathrm{~mm}, 7 \mathrm{~mm}$ and $8 \mathrm{~mm}$ sizes were mounted in turns on the barrel machine and used to run the experiment. As the samples were fed in to the machine, the feed time and grating time were recorded. The pulp were collected through the discharge chute and sorted into two categories (completely grated and partially grated). Their weights were recorded and the experiment was repeated with each sample. The corresponding feed time and grating time were taken and average value recorded.

Machine Efficiency: In calculating the machine efficiency of the single and double barrel grating machine, the formula in equation (1) was used.

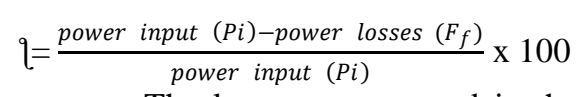

The losses encountered in the course of the machine operation were taken as frictional losses $\left(F_{f}\right)$ which is as a result of surface contacts between the belt and the pulley (both the driving and the driven). The frictional force $\left(F_{f}\right)$ is given by equation (2).

$$
F_{f}=\mu R
$$

For friction on an incline plane

$F_{f}=\mu R=\frac{m g \operatorname{Sin} \theta}{m g \operatorname{Cos} \theta}=\tan \theta$

Where, $F_{f}=$ frictional losses,

$\mu=$ coefficient of friction

$\theta=$ angle of friction, and

$R=$ normal reaction

Therefore $\quad F_{f}=\tan \theta$

Where $\tan \theta$ Surface contacts between the Flat belt and the pulley

Grating Efficiency: The grating efficiencies of the machines were checked to establish to what extent the machines can grate with respect to the different sizes of abrasive grating surfaces. This was achieved using equation (5) thus;

$$
\begin{aligned}
& G_{\uparrow}=\frac{\text { mass of cassava fed in }(\mathrm{kg}) \text { - mass of partially grated cassava }(\mathrm{kg})}{\text { mass of cassava fed in }(\mathrm{kg})} X 1000 \\
& \text { which is same thing as saying } \\
& G_{q}=\frac{\text { mass of completly grated cassava }(\mathrm{kg})}{\text { mass of cassava fed in }(\mathrm{kg})} \times 100
\end{aligned}
$$

Moisture Content: By applying the equation similar to that reported by Bu petal (2008). The moisture content in percentage dry basis $(\% \mathrm{db})$ was determined thus

Thus: $M_{c}(\% \mathrm{db})=\frac{M_{i}-M_{f}}{M_{f}} X 100$

$M_{c}(\% \mathrm{db})=$ Moisture content on dry basis.

$M_{i}=$ Initial weight of sample + weight of Petri dish.

$M_{f}=$ Final weight of sample at constant weight

\section{Design of Experiment}

Design Expert software (version 7.0.7.1.) was used in this study to design the testing and optimizing the performance of the grater. The experimental design employed in this work was a two-level-two factor full factorial design. Central Composite Response Design and 13 (i.e. $2^{2}+2 * 2+5$ ) test runs were performed for fresh and stored samples each. Abrasive surface size and feed rate were selected as independent factors for the optimization study. The response chosen was the efficiency. Five replications of centre points were used in order to predict a good estimation of errors and testing were performed in a randomized order. The actual and coded levels of each factor are shown in Table 1 . The coded values were designated by -1 (minimum), 0 (centre),+1 (maximum), $-\alpha$ and $+\alpha$. Alpha is defined as a distance from the centre point which can be either inside or outside the range, with the maximum value of $2 n / 4$, where $n$ is the number of factors. It is noteworthy to point out that the software uses the concept of the coded values for the investigation of the significant terms, 
thus equation in coded values is used to study the effect of the variables on the response. The empirical equation is represented thus:

$\mathrm{Y}=\beta_{0}+\sum_{i=1}^{2} \beta_{i} X_{i}+\sum_{i=1}^{2} \beta_{i i} X^{2}{ }_{i}+\sum_{i=1}^{2} \sum_{j=i+1}^{2} \beta_{i j} X_{i} X_{j}$

$\mathrm{Y}=\quad$ Response

$\beta_{0}=\quad$ Constant term

$\sum_{i=1}^{2} \beta_{i}=\quad$ Summation of coefficient of linear terms

$\sum_{i=1}^{2} \beta_{i i}=\quad$ Summation of quadratic terms

$\sum_{i=1}^{2} \sum_{j=i+1}^{2} \beta_{i j}=$ summation of coefficient of interaction terms

$X_{i} X_{j}=\quad$ independent variables

The transformation of coded value to actual value can be obtained using the equation (9):

$X_{i}=\frac{x_{i}-\bar{x}}{\Delta x}$

Where:

$X_{i}=$ the coded value of $\mathrm{i}$-th factor

$x_{i}=$ the current actual value

$\bar{x}=$ mean value for actual values

$\Delta x=$ difference between the mean actual value and actual value

The levels and ranges of the studied factors are presented in Table 1. With the design matrix of all the factors in coded and actual values the runs were carried out.

Table 1: Studied Range of Each Factor in Actual and Coded Form

\begin{tabular}{|l|l|l|l|l|l|l|}
\hline Factor & Units & Low level & High level & $-\alpha$ & $+\alpha$ & 0 level \\
\hline Abrasive surface size (A) & $\mathrm{mm}$ & $5(-1)$ & $7(+1)$ & $4(-2)$ & $8(+2)$ & 6 \\
\hline Feed rate (B) & $\mathrm{kg} / \mathrm{min}$ & $10(-1)$ & $13(+1)$ & $9(-2)$ & $14(+2)$ & 11.5 \\
\hline
\end{tabular}

\section{Results And Discussion}

The results of the moisture contents of the three species of fresh and stored cassava are shown in Table 2. It was observed that the moisture content varies from specie to specie as well from fresh to stored conditions. The average moisture content of $74.4 \% \mathrm{db}$ for fresh sample and $61.4 \% \mathrm{db}$ for stored sample were found.

Table 2: Moisture Content Test Results of Freshly and Stored Cassava Samples

\begin{tabular}{|l|l|l|l|l|l|l|}
\hline Samples & Weight of Petri dish $(\mathrm{g})$ & $M_{i}(\mathrm{~g})$ & $\mathrm{M}_{\mathrm{f}}(\mathrm{g})$ Fresh & $M_{f}(\mathrm{~g})$ Stored & $M_{c}(\% \mathrm{db})$ Fresh & $\mathbf{M}_{\mathrm{c}}(\% \mathrm{db}) \mathrm{Stored}$ \\
\hline UMUCASS 36 & 22.6 & 150 & 98.3 & 103.3 & 75.6 & 67.0 \\
\hline UMUCASS 37 & 22.6 & 150 & 98.9 & 107.2 & 74.5 & 61.0 \\
\hline UMUCASS 38 & 22.6 & 150 & 99.5 & 110.4 & 73.5 & 56.3 \\
\hline Average & 22.6 & 150 & 98.9 & 106.9 & 74.5 & 61.4 \\
\hline
\end{tabular}

\section{Performance Evaluation of the Grater Using Fresh Cassava Samples}

The performance efficiency of the grater for fresh cassava samples depends on the results showing significant variation for combination of process parameters. The empirical relationship between performance efficiency (Y) and the variables in coded values obtained by using the statistical tool were given by equations (10) and (11) for fresh and stored cassava, respectively.

$$
\begin{aligned}
& Y=96.59-1.08 \mathrm{~A}-0.11 \mathrm{~B}-1.75 \mathrm{AB}-10.64 \mathrm{~A}^{2}-13.76 \mathrm{~B}^{2} \\
& Y=98.12+3.33 \mathrm{~A}+3.40 \mathrm{~B}-8.50 \mathrm{AB}-5.53 \mathrm{~A}^{2}-8.32 \mathrm{~B}^{2}
\end{aligned}
$$

Where $\mathrm{Y}$ is the response variable (performance efficiency) and $\mathrm{A}-\mathrm{B}$ are the coded values of the independent variables. The above equation represents the quantitative effect of the factors (A and B) upon the response (Y). Coefficients with one factor represent the effect of that particular factor while the coefficients with more than one factor represent the interaction between those factors. Positive sign in front of the terms indicates synergistic effect while negative sign indicates antagonistic effect of the factor. The adequacy of the above proposed models were tested using the Design Expert sequential model sum of squares and the model test statistics. For fresh cassava test results, the model F-value (9634.92) of the quadratic model is large relatively. And from the statistics test, the coefficient of determination. $\left(\mathrm{R}^{2}=0.9999\right)$ is high, and the adjusted $\mathrm{R}^{2}(0.9998)$ is in close agreement with the predicted $\mathrm{R}^{2}(0.9992)$ value. Similarly for stored cassava test results, the model Fvalue is (552.67) of the quadratic model is large relatively. And from the statistics test, the coefficient of determination $\left(\mathrm{R}^{2}=0.9975\right)$ is high, and the adjusted $\mathrm{R}^{2}(0.9957)$ is in close agreement with the predicted $\mathrm{R}^{2}$ (0.9855) value. 
The experimental data were also analyzed to check the correlation between the experimental and predicted performance efficiency of the grater on fresh cassava, and the actual and predicted plots were shown in Figures 2 and 3 for fresh and stored cassava respectively. It can be seen from the Figures that the data points on the plot were reasonably distributed near to the straight line, indicating a good relationship between the experimental and predicted values of the response, and that the underlying assumptions of the above analysis were appropriate. The result also suggests that the selected quadratic model was adequate in predicting the response variables for the experimental data.

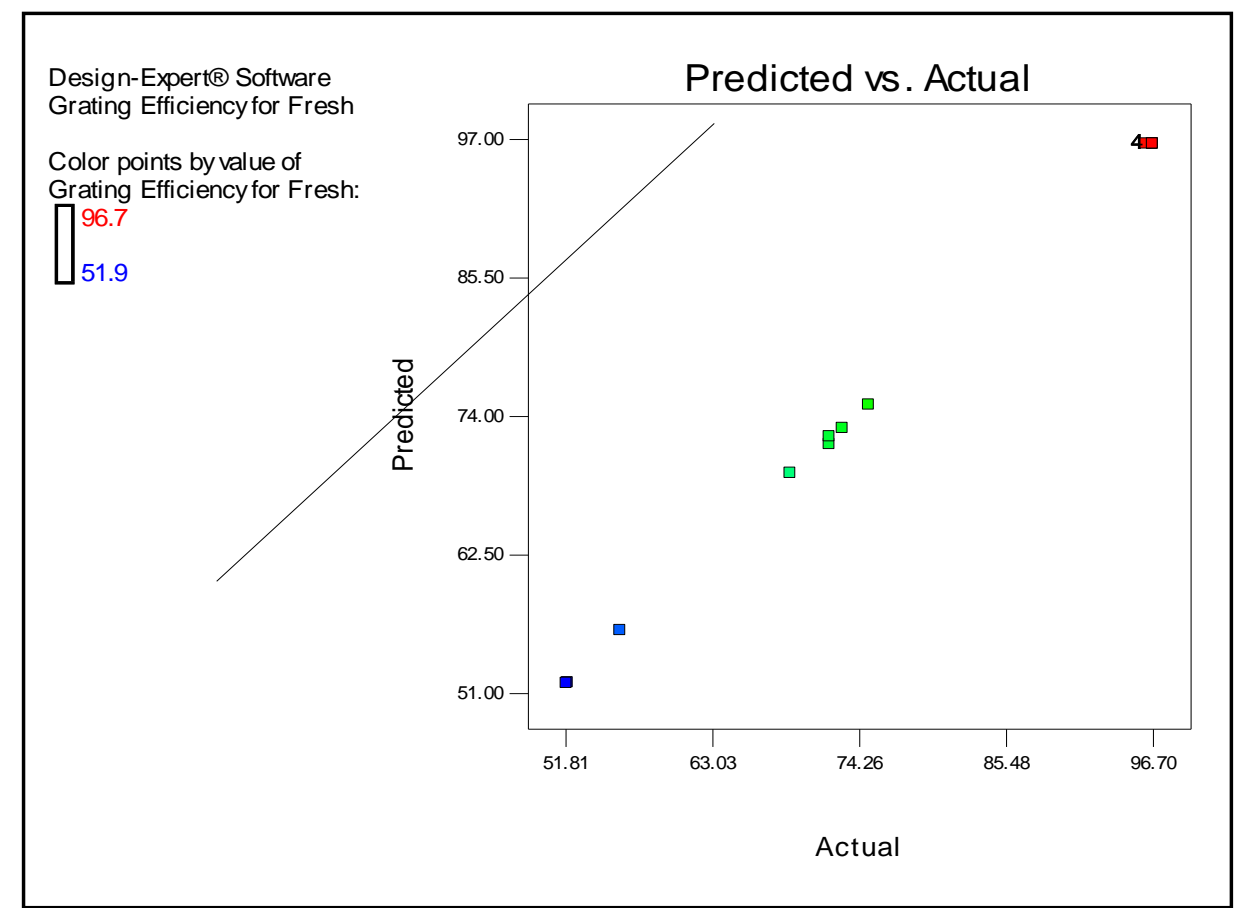

Figure 2: Predicted values versus actual values for the grater on fresh cassava

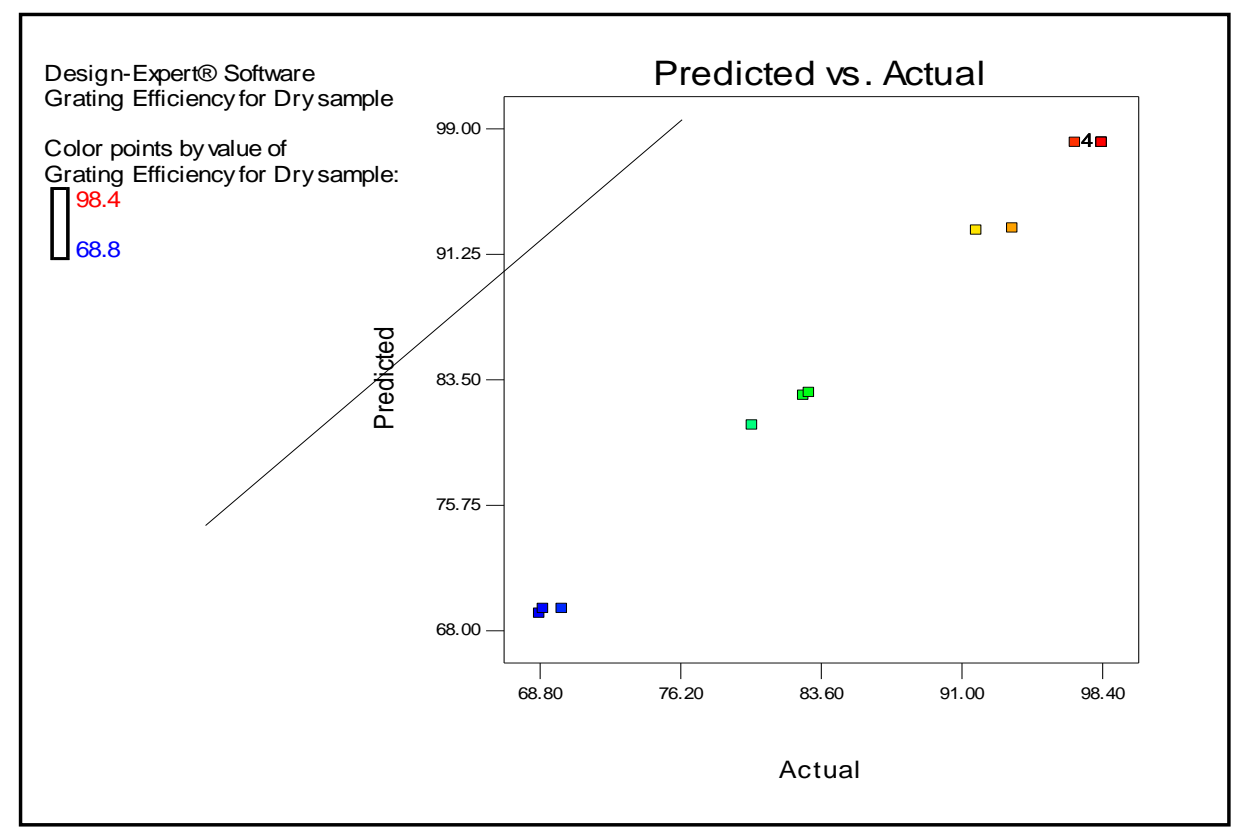

Figure 3: Predicted values versus actual values for the grater on stored cassava

\section{Three Dimensional Surface and Contour Plots for the Gater Performance Efficiency}

The 3D response surface and contour plots were generated to estimate the effect of the combinations of the independent variables on the performance efficiency. The 3D plots are shown in Figure 4 and 5 for fresh and stored cassava and the contour plots are shown in Figure 6 and 7, respectively. 


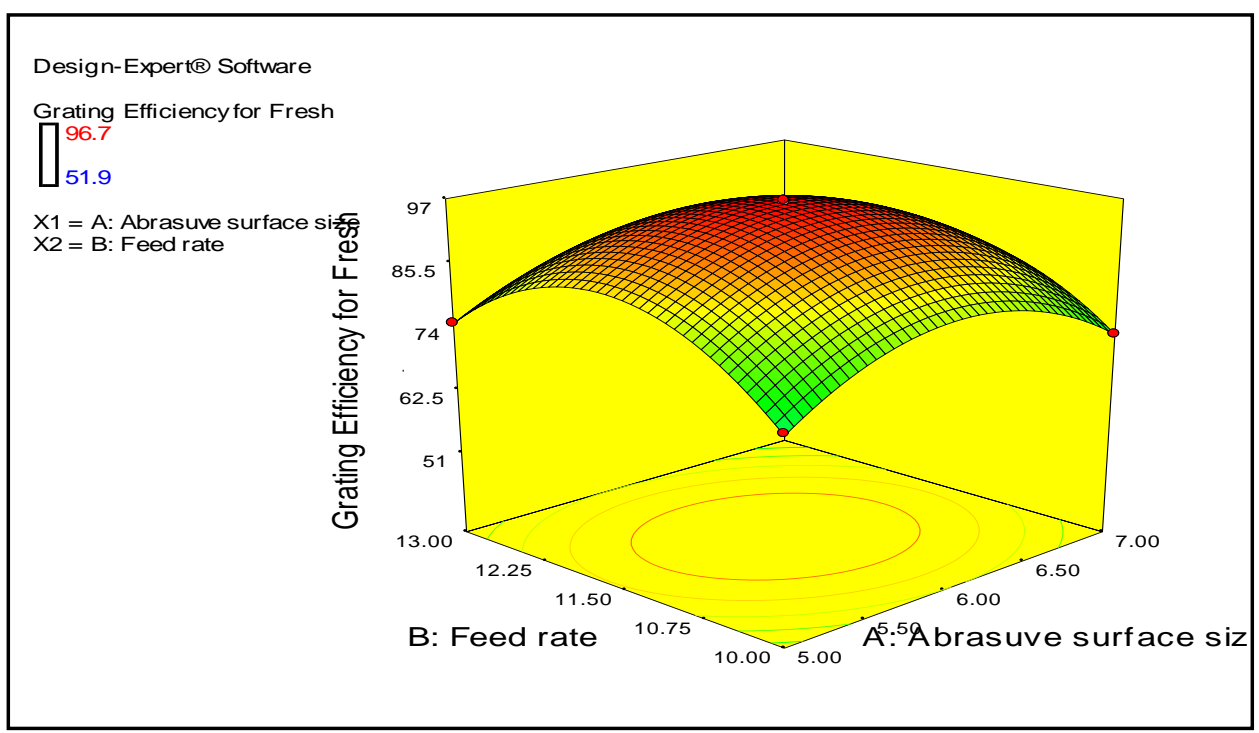

Figure 4: 3D Plot showing impact of feed rate and abrassive surface size on the grating efficiency for fresh cassava

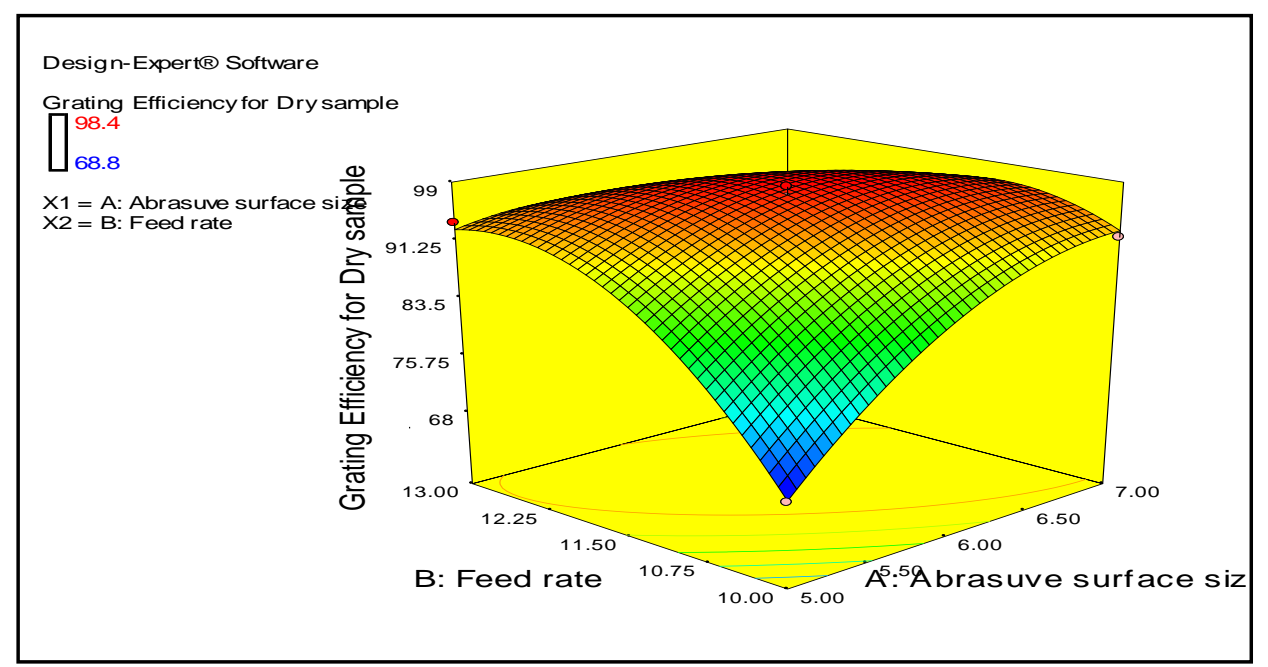

Figure 5: 3D Plot showing impact of feed rate and abrassive surface size on the grating efficiency for stored cassava

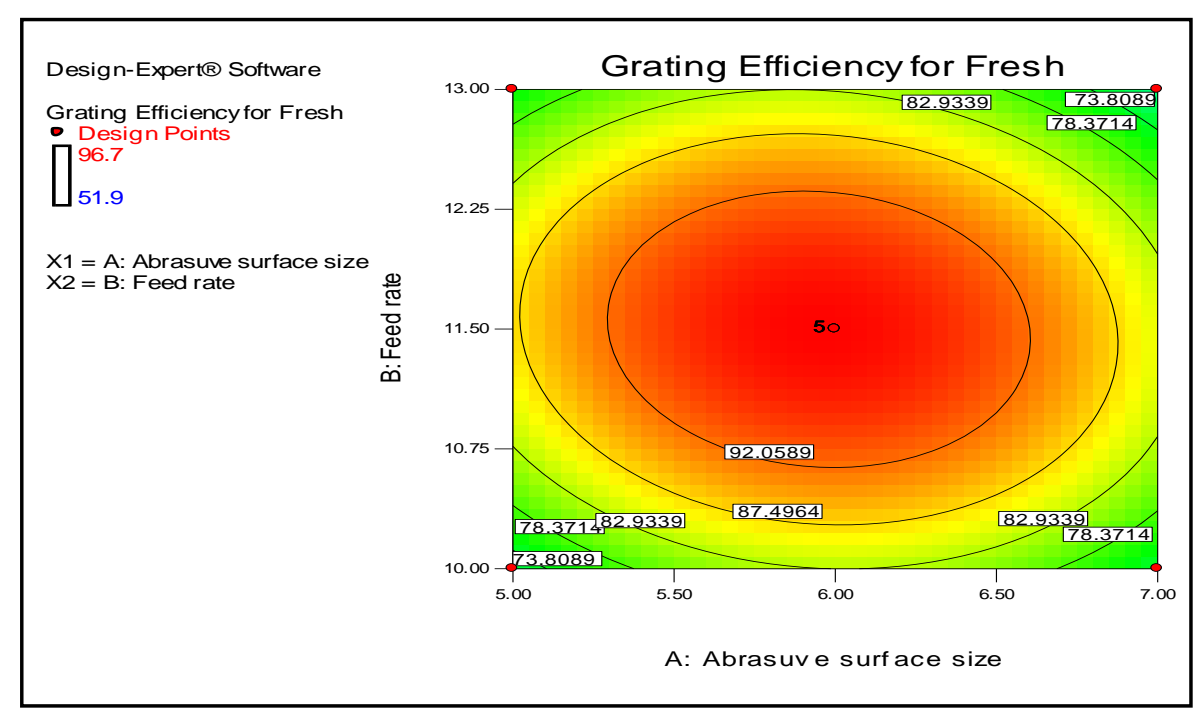

Figure 6: Contour Plot showing impact of feed rate and abrassive surface size on the grating efficiency for fresh cassava 


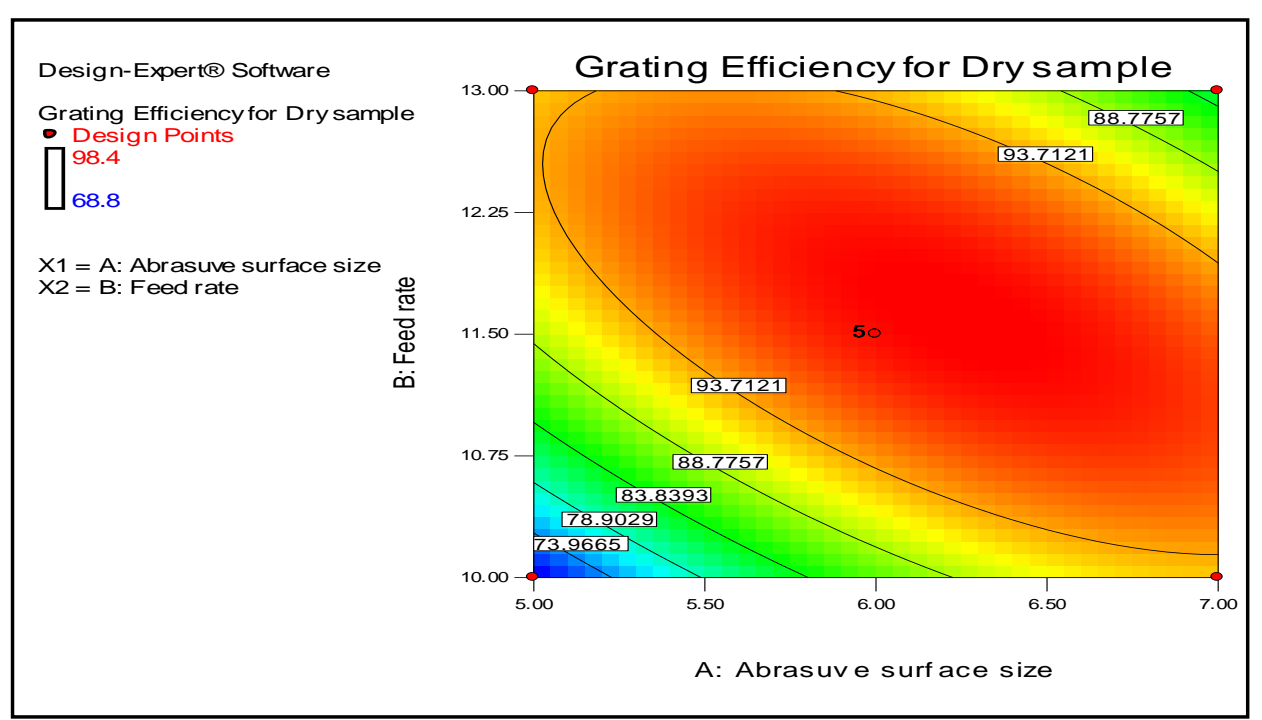

Figure 7: Contour Plot showing impact of feed rate and abrassive surface size on the grating efficiency for stored cassava

Figures 4 to 7 shows the dependency of performance efficiency on feed rate and abrasive surface size. As can be seen from the figures, performance efficiency $(\%)$ increases as both the abrasive surface size and feed rate increased up to a point of these variables and then decreased. This is as a result of large holes on the abrasive surface size. The results also showed that better performances were observed the machine grated stored cassava samples than when it grated fresh cassava sample. Specifically, the grating efficiencies at different points on the variables show that the fresh cassava are within the range of $51.9 \%$ to $96.7 \%$ while that of the stored cassava are of the range $68.8 \%$ to $98.4 \%$. This clearly shows that moisture content affects the performance of grating machine.

\section{Optimization of the Performance Efficiency and Validation of the Models}

The grater performance was optimized with the design expert to obtain optimal conditions. The measured value and predicted values for fresh and stored cassava are shown in Table 8. For validation purposes, a test run under the obtained optimum operating conditions was carried out in order to evaluate the precision of the quadratic models; Comparing the experimental and predicted results for fresh cassava, it can be seen that the error between the measured and predicted is less than $0.5 \%$, therefore it can be concluded that the generated model has sufficient accurancy to predict the machine performance. Similarly, the error in the experimental and predicted results is less than $0.7 \%$. Hence, the generated model also has sufficient accuracy to predict the machine performance.

Table 8: Performance Efficiency Optimum Operating Conditions

\begin{tabular}{|l|l|l|l|l|}
\hline Type of Cassava & $\begin{array}{l}\text { Abrasive surface } \\
\text { sze }(\mathrm{mm})\end{array}$ & $\begin{array}{l}\text { Feed rate (kg/min) } \\
\text { B }\end{array}$ & $\begin{array}{l}\text { Measured } \\
\text { Efficiency }(\%)\end{array}$ & $\begin{array}{l}\text { Predicted } \\
\text { Efficiency }(\%)\end{array}$ \\
\hline Fresh Cassava & 6 & 11.5 & 96.2 & 96.6 \\
\hline Stored Cassava & 6 & 11.6 & 98.0 & 98.6 \\
\hline
\end{tabular}

From table 8 it can be observed that the grating machines perform better with stored or samples with less moisture content.

\section{Conclusion}

In this study performance and optimization evaluation of single barrel cassava grating machine on selected fresh and stored cassava species has been carried out. The selected species were UMUCASS 36, UMUCASS 37, UMUCASS 38. It was observed that the moisture content varies from specie to specie as well as fresh or stored condition. The average moisture content of $74.4 \% \mathrm{db}$ for fresh sample and $61.4 \% \mathrm{db}$ for stored sample were found. The selected species for fresh and stored cassava were used to carry out performance evaluation with varying feed rate and abrasive surface hole sizes of the cassava grater. The performances efficiency of the machines were analyzed using Design Expert Software version 7.07.1 to determine the optimum operating condition for best efficiencies.

Better performances were observed when the machine grated stored cassava samples than when it grated fresh cassava samples. This shows that moisture content affect the performance of grating machine. The 
design expert software analysis of the performance of the machine predicted optimum operating condition as follows: $6 \mathrm{~mm}$ abrasive surface hole sizes for both fresh and stored cassava, feed rate of $11.5 \mathrm{~kg} / \mathrm{min}$ and $11.6 \mathrm{~kg} / \mathrm{min}$ respectively for fresh and stored samples, $96.6 \%$ and $98.6 \%$ for fresh and stored grating efficiency. These results prove that the grating machines perform better with stored or samples with less moisture contents.

\section{References}

[1]. Adejumo A. O. D, Oradugba O.B, Ilori T. A, Adenekan M. O (2011). Development and Evaluation of a Cassava Chipping Machine. Journal of Raw Materials Research, 1-7.

[2]. Agbetoye O., Oyedele A. (2005). Development and testing of a dual grain sifter. Proceeding of the Nigerian Institution of Agricultural Engineers, 2005/192-193.

[3]. Akanbi O. P. (2014). Performance and sensitivity evaluation of a developed cassava-grating machine. Analle University Journal 21:28-34

[4]. Akande, F. B., Adebayo, A. O and Busari, R. A. (2008). Design, fabrication and testing of manually operated cassava chipping machine. Proceedings of the Nigerian Institution of Agricultural Engineers, Adamawa, 1-14.

[5]. Akinyemi J. O., Akinlua O. and Okunaya, A. O. (1999), Design and testing of a cassava grater. International Journal of Tropical Agriculture, 17 (14): 103-108.

[6]. Chinsman B. and Fiagan Y. S. (1987). Post harvest technologies and root crops in Africa. Evaluation and Recommended Improvements in Tropical Root Crops in Root Crops and the African Food Crises. Crisis E. R., Tarry, M. O. Akoroda, M. O. and Arene O. B. (eds). 17-25.

[7]. Davies R.M., (1991). A survey of cassava Processing Machinery in Oyo State of Nigeria, Project Report, Agricultural Engineering Department, University of Ibadan, Nigeria.

[8]. FAO, Food and Agricultural Organization (2007). Food and Agricultural Organization of United Nations Annual statistics. Rome, Italy. International institute for Tropical Agriculture

[9]. IITA, International Institute of Tropical Agriculture (1990). Cassava in Tropical Africa, a reference manual. 83- 100

[10]. Ndaliman M. B. (2006). Development of Cassava Grating Machine: A Dual-Operational Mode. Leonardo Journal of Sciences. 9 , 103-110.

[11]. Malomo O., Bello E. K. Adekoyeni O. O. Jimoh M. O. (2014). Performance Evaluation of an Automated Combined Cassava Grater/Slicer. International Invention Journal of Biochemistry and Bioinformatics 2(3):30-36.

[12]. Ndaliman M. B., (2006). Design and construction of a pedal operated cassava grinder, Unpublished Manuscript.

[13]. Oyesola G. O. (1981). Technology Processing Cassava and Utilization, Advisory Leaflet No. 3 Cassava and Garri Storage, NCAM, Kwara State, Nigeria, 